\title{
Effect of Unwanted Pregnancy on Antenatal Care in Rural and Urban Areas In Indonesia
}

\author{
Martya Rahmaniati ${ }^{1}$, Desya Mulyaningrum ${ }^{2}$ \\ \{tya_makful@yahoo.com ${ }^{1}$, desyamulyaningrum@gmail.com ${ }^{2}$ \} \\ Faculty of Public Health, Universitas Indonesia ${ }^{1,2}$
}

\begin{abstract}
The definition of unwanted pregnancy is a pregnancy that occurs outside of planning, because the husband or wife partner does not want to use contraception, there is no access to family planning services which causes pregnancy. The purpose of this study about unwanted risk factors for pregnancy to the completeness of antenatal care [ANC]. The study design using IDHS study design with cross sectional design. The sample in this study was a live birth in the five years prior to the survey report birth weight rural and urban areas in Indonesia. Data analysis used multivariate logistic regression analysis for risk factor models. Unwanted pregnancies have an influence on ANC in both rural and urban areas. Individual variables that affect rural areas are influenced by employment, economic status, age and parity, while in urban areas they are influenced by economic status and age.
\end{abstract}

Keywords: Antenatal Care, Public Health, Rural, Urban, Unwanted Pregnancies

\section{Introduction}

Unwanted pregnancy is a pregnancy that occurs outside of planning, because the husband or wife does not want to use contraception, there is no access to family planning services and the couple is physically and psychologically unprepared and reject the occurrence of pregnancy. Meanwhile, describing an unintended pregnancy is an unwanted pregnancy and a mistimed pregnancy. Unwanted pregnancy, that is, an unwanted pregnancy at any time or not wanting to have another child. Whereas, mistimed pregnancy is a pregnancy that is not timely, the pregnancy is anticipated but not at a certain time [1].

The proportion of unwanted pregnancies at all in Indonesia is based on data from the 2007 Indonesia Basic Health Survey [IDHS] of 7.4\% of 18,168 births of women aged 15-49 during the five years before the survey, including pregnancy during the survey. Then based on the 2012 IDHS data, the proportion of unwanted pregnancies at all in Indonesia was 7.1\% from 18,898 
births of women aged 15-49 during the five years before the survey, including pregnancy during the survey. Furthermore, based on the 2017 IDHS, the proportion of unwanted pregnancies at all in Indonesia was 7.1\% of the 18,952 births of women aged 15-49 during the five years before the survey. It can be seen from the two periods of the IDHS that the proportion of unwanted pregnancies has not changed and is still stable so that a good birth planning pattern is needed.

The need for effective programs and strategies to improve access to contraceptive services and information related to contraceptive tools and methods. Increasing access to family planning services is the key to reducing unwanted pregnancies, these efforts require crosssectoral policy makers to increase access to family planning services. Improved access needs to be accompanied by an increase in the quality of care and availability of information about the effective use of family planning methods [2,3]. Examination of pregnant women [Antenatal Care] both physically and mentally with the aim to save the mother and child during the pregnancy, childbirth and the puerperium so that conditions can return to normal. Determinants of unwanted pregnancies in Indonesia are the level of maternal education, area of residence, status of living with a partner, parity, complications of pregnancy, use of contraception and illnesses suffered by the mother. Information and education on how to prevent the occurrence of unwanted pregnancy still needs to be improved [4].

Early antenatal care $[\mathrm{ANC}]$ initiation is a way to detect the early management of potential complications related to pregnancy. Although some research shows that ANC does not always show a relationship with pregnancy to maternal age and parity [5]. Unwanted pregnancy can increase the risk of problems for the mother and the baby she is carrying. If the pregnancy is not planned before conception, then the woman may not get optimal health care . The purpose of this study is to obtain an unwanted pregnancy model with the completeness of the ANC in urban and rural areas. Many aspects of health care during pregnancy or ANC that need to be considered to ensure good delivery outcomes, one of which is a good final impact of childbirth is the weight of the baby born.

\section{Methods}

The subjects of this study were mothers who gave birth alive in the five years before the survey with a report having a history of pregnancy examinations and residing in rural and urban areas in Indonesia. This study uses secondary data from the 2017 IDHS data, with the 
approval of the IDHS for further analysis. The research design of the SDKI is a cross sectional design because the measurements and observations are made at one time. The dependent variable ANC visits made by mothers during pregnancy with a high risk category if the ANC visit is less than 4 times during pregnancy and low risk if the ANC visit is more than or equal to 4 times during pregnancy.

The main independent variable is the unwanted pregnancy at all by the mother. The unwanted pregnancy desire categories are divided into unwanted pregnancy and desired pregnancy. Pregnancy is not desired if the respondent answers that he does not want to at all, while pregnancy is desired if he wants to get pregnant soon, wants to get pregnant later, and wants to get pregnant, while the other variables are the level of education, work status, family economic level, age at risk of giving birth, complications of pregnancy and parity.

The data used in this study were obtained from a questionnaire of women of childbearing age from the Basic Health Survey Indonesia data in 2017. Large samples were obtained using a different sample size proportions, the number of samples obtained for urban areas was 8,104 and rural areas were 7,919. needed. Data processing uses descriptive statistical analysis which aims to provide a descriptive description of each variable used in research and multivariate analysis with logistic regression statistical tests because the dependent and independent variables in this study are categorical data.

\section{Results and Discussions}

Researchers can not control the quality of secondary data from survey interviews with female respondents aged 15-49 years who had a live birth in the five years prior to the survey report birth weight rural and urban areas in Indonesia. In the 2017 IDHS, recall can occur. Recall bias is the bias caused by respondents' mistakes in remembering events related to research variables. In this study recall bias can occur when asking the weight of a baby born by a respondent, even though it has been minimized by limiting live births in the 5 years before the survey. In addition, recall bias can occur when asking the total number of ANC visits made during pregnancy

Pregnancy and problems contribute to a very high proportion of maternal deaths. Around 830 women die from pregnancy or related complications around the world every day [6]. Unwanted pregnancy is an important public health problem throughout the world. It not only affects women, but also affects their families and communities [7]. 
Table 1 shows that unwanted pregnancy among respondents in urban areas is greater [8.9\%] than in rural areas [6.3\%]. Women in rural areas are more likely to experience unwanted pregnancies than in urban areas. This study shows the same results with research conducted in Egypt [7]. These results do not agree with other studies conducted in Sudan [8] which reported no significant differences between urban and rural women.

Table 1. Distribution of Respondents by Pregnancy Category in Urban and Rural Areas

\begin{tabular}{lcccc}
\hline \multirow{2}{*}{$\begin{array}{c}\text { Pregnancy } \\
\text { Category }\end{array}$} & \multicolumn{2}{c}{ Urban } & \multicolumn{2}{c}{ Rural } \\
\cline { 2 - 5 } & Frequency [n] & Precentage [\%] & Frequency [n] & Precentage [\%] \\
\hline wanted & 7.382 & 91,1 & 7.416 & 93,7 \\
unwanted & 722 & 8,9 & 502 & 6,3 \\
\hline Total & 8.104 & 100 & 7.918 & 100 \\
\hline
\end{tabular}

[Source: the data processing, 2019]

An unwanted pregnancy results in unhealthy behavior during pregnancy [9]. Thus, unwanted pregnancy has a direct relationship with the utilization of maternal health care services during pregnancy such as delayed initiation, or low attendance at antenatal care visits $[10,11]$.

Unwanted pregnancies pose many important public health risks, and their adverse consequences have been extensively studied [12] Several studies explain the relationship between unwanted childbirth and maternal health problems, such as maternal depression $[13,14]$, anxiety, poor psychological well-being and poor use of ANC or childbirth care. A study states that women who experience an unwanted pregnancy are less likely to seek pregnancy care than women who do want a pregnancy. However, most of these studies are carried out in developed countries while the evidence is limited and sometimes inconsistent in developing countries [15].

Community in Indonesia, the work is an important thing that should be a priority as it relates to the revenue that can be used for subsistence. This is a model that has been developing, especially in developed countries like Indonesia. A pregnant woman in a urban area is more likely to spend her time doing work activities that are owned compared to having to visit antenatal care. In communities with a lower middle economy, behavior to make work a priority 
is a natural thing considering that so far the existing health services have not been able to provide the best service to the community, especially in people with a lower middle economy. This will indirectly reduce the motivation of pregnant women to conduct antenatal care visits

Table 2. Relationship between pregnancy and ANC in urban and rural areas

\begin{tabular}{|c|c|c|c|c|c|c|}
\hline \multirow{2}{*}{ Pregnancy Category } & \multicolumn{2}{|c|}{ ANC Low risk } & \multicolumn{2}{|c|}{ ANC High Risk } & \multirow[t]{2}{*}{$P$ value } & \multirow[t]{2}{*}{ OR } \\
\hline & $\mathrm{n}$ & $\%$ & $\mathrm{n}$ & $\%$ & & \\
\hline \multicolumn{7}{|c|}{ Urban } \\
\hline Wanted & 7.279 & 91,6 & 427 & 81,5 & \multirow{2}{*}{0,001} & \multirow{2}{*}{3,12} \\
\hline Unwanted & 669 & 8,4 & 97 & 18,5 & & \\
\hline \multicolumn{7}{|c|}{ Rural } \\
\hline Wanted & 6.690 & 94,7 & 668 & 90 & \multirow{2}{*}{0,001} & \multirow{2}{*}{2,55} \\
\hline Unwanted & 377 & 5,3 & 74 & 10 & & \\
\hline
\end{tabular}

[Source: the data processing, 2019]

Table 2 shows that unwanted pregnant with ANC examination that has a high risk in urban areas shows a greater value [18.5\%] compared to respondents in rural areas. Studies conducted in developing and developed countries shows that women with unwanted pregnancies do not use ANC or do not receive adequate care during pregnancy $[11,16]$. This can be caused by women who are financially and emotionally unprepared for the demands of pregnancy and childbirth [17] and also, most likely due to delays in recognizing pregnancy. The results show a significant relationship and the OR values are not much different, where the OR values in urban areas indicate that mothers who have a desire not to become pregnant are at risk of 3.12 not to do an ANC examination.

Table 3 shows the characteristics of respondents in rural areas more high risk mothers in all variables compared to mothers in urban areas. Higher education of a mother who does not want a pregnancy to do ANC as much as $81 \%$ in urban areas and $59.2 \%$ in rural areas. This shows that education has an important role in the knowledge of a pregnant woman to carry out antenatal care [ANC]. In the status of working mothers, pregnant women who work continue to do ANC, this can be caused by working mothers who can have income so that they can carry out antenatal care.

Table 3. Characteritic of Responden

\begin{tabular}{llll} 
Variable & Category & Urban & Urban \\
\cline { 2 - 3 }
\end{tabular}




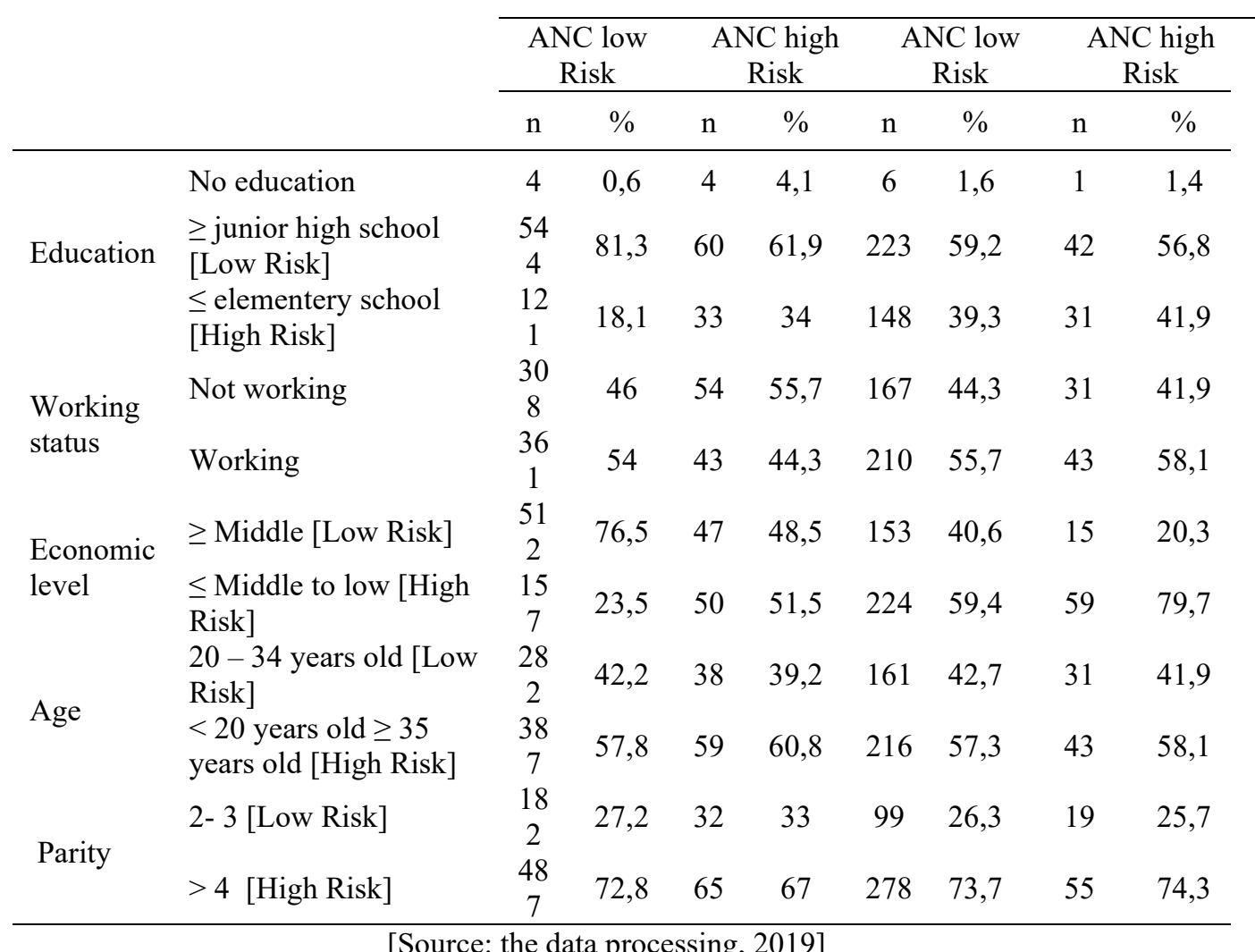

[Source: the data processing, 2019]

Unwanted pregnancy and in early pregnancy there is an effort to end of ANC examination. Mothers who experience an unwanted pregnancy have a 1.79 chance of not taking pregnancy care compared to the desired pregnancy; have the same opportunity for behavior that does not provide exclusive breastfeeding and does not provide complete basic immunization. The results of stratification analysis show the effect of unwanted pregnancy status on behavior: pregnancy care; exclusive breastfeeding and complete basic immunization which is also influenced by economic status. The wealthier tend to take care [18].

Table 4. Multivariat Analysis Result

\begin{tabular}{lllll}
\hline Variable & B & P-value & OR & \multicolumn{2}{c}{$95 \%$ C.I } \\
\cline { 3 - 5 } & & & Lower & Upper \\
\hline
\end{tabular}




\begin{tabular}{llllll}
\multicolumn{1}{c}{ Urban } & & & & & \\
\hline Age & 0,423 & 0,001 & 1,527 & 1,237 & 1,885 \\
Economic status & 0,980 & 0,001 & 2,665 & 2,175 & 3,264 \\
\hline \multicolumn{1}{c}{ Rural } & & & & & \\
\hline Education & 0,171 & 0,040 & 1,187 & 1,008 & 1,397 \\
Working & $-0,212$ & 0,007 & 0,809 & 0,694 & 0,943 \\
Economic status & 0,638 & 0,001 & 1,893 & 1,577 & 2,274 \\
Age & 0,338 & 0,001 & 1,403 & 1,191 & 1,651 \\
Parity & 0,285 & 0,003 & 1,330 & 1,100 & 1,608 \\
\hline
\end{tabular}

[Source: the data processing, 2019]

Multivariate results indicate that unwanted pregnancy of ANC in urban areas is influenced by age and economic status variables affecting unwanted pregnancy, whereas in rural areas the variables that influence are education level [moderate education, graduated junior high school], employment, economic status, age and parity.

Economic status is the same variable of the relationship model between unwanted pregnant and ANC visits in rural and urban areas. Family income is all revenues in cash or goods either from the other party as well as of the parties themselves. Per capita income is the average family income of a family obtained from the income distribution of all family members. The intended income is a level of income derived from basic work and side jobs of parents and other family members [19]. Family income is an enabling factor for someone to utilize health services. Family income also determines the socioeconomic status of the family. Socio-economic is a picture of a person's level of life in society that is determined by variables of income, education and employment, because this can affect aspects of life including health care. A pregnant woman who has an adequate family income will indirectly make it easier for pregnant women themselves to visit antenatal care for pregnant women not to think about financing must be prepared to perform antenatal care visits $[20,21]$.

Age of mothers who are at risk of influencing mothers in carrying out antenatal care in cities and villages. Age influences one's comprehension and mindset. Increasing age will also develop the power of catching and mindset, so that the knowledge gained is getting better, this is as a result of the experience and maturity of the soul, so that the more mature the age of 
pregnant women can influence in receiving information about antenatal care and visits during pregnancy. The more a woman is old enough, the better the level of maturity in thinking so that she will be motivated to have a pregnancy check up, also to know the importance of antenatal care. The younger the mother's age, the less understanding of the importance of antenatal care [22].

The level of maternal education is related to the incidence of unwanted pregnancy in Indonesia. The higher the level of maternal education, the risk of unwanted pregnancy also decreases. In other words education will reduce the risk of unwanted pregnancy [4]. This is consistent with research conducted in India which shows the higher the level of maternal education, the unwanted pregnancy decreases. A woman's education level is related to her ability to capture information such as awareness, value of small family benefits and knowledge about contraception and family planning. Illiterate women or those with low education are more prone to unwanted pregnancies because their ability to capture information to prevent the incidence of unwanted pregnancy is lower than those with higher education [23]. A low level of maternal education increases the risk of having a low birth weight compared to a high level of education. Mothers with low education tend to have behaviors that do not support health [24]. Pregnant women who have an educational background in a good category, in themselves already have a basis for being able to think logically to respond to antenatal care visits. Mothers will try to weigh the pros and cons of conducting antenatal care visits. If what appears is a positive aspect then the mother will be motivated to make antenatal care visits, but if what appears is a negative aspect, pregnant women will certainly be reluctant to make antenatal care visits.

Parity has a significant relationship with the incidence of unwanted pregnancy. The more children ever born, the higher the chance of an unwanted pregnancy. The 2012 IDHS results showed that the proportion of unwanted pregnancies also increased with the sequence of children born. Research in Ethiopia and India also found that the more children ever born the possibility of a desired pregnancy is also greater. Women who have many children but are still pregnant and unwanted pregnancies may be due to unmet need for contraception or because of the impact of contraceptive failure. Mothers who have given birth to many children also feel that the number of children who have reached the ideal number so that with another pregnancy the possibility of unwanted pregnancy is also greater $[23,25]$. 
The results of an analysis that show that unwanted pregnancies tend to be at risk 3.2 times make mothers not want to check their pregnancy compared to pregnancies that are desirable and planned. The issue of pregnancy care is an important key in implementing maternal and other health programs. Health care workers who understand the status of unwanted pregnancy need to provide education so that all pregnant women want to do a pregnancy checkup and still pay attention to the nutritional intake and health care needs of their children since the fetus.

\section{Conclusion}

The results of this study indicate that economic status and age are important variables in urban and rural areas. Where both of these variables both have a high OR value for antenatal care. This unwanted pregnancy can affect the behavior of the mother not to do or if it does not perform optimally, visits to antenatal care, childbirth, childbirth, and infants.

Acknowledgements. The author would like to thank Desya Mulyaningrum for granting permission to use the IDHS data for 2017 and assisting in the processing of the data.

\section{References}

[1] Shah PS, Balkhair T, Ohlsson A, Beyene J, Scott F, Frick C. Interntion to Become Pregnant and Low Birth Weight and Preterm Birth: A Systematic Review. Maternal and Child Health Journal. 2011;15[2]:205-16.

[2] Eliason S, Baiden F, Yankey BA, Awusabo-Asare K. Determinantas of Unintended Pregnancies in Rural Ghana. BMC Pregnancy and Childbirth. 2014;14[261].

[3] Ikamari L, Izugbara C, Ochako R. Prevalence and Determinants of Unintended Pregnanccy among Women in Nairobi, Kenya. BMC Pregnancy and Childbirth. $2013 ; 13[69]$.

[4] Saptarini I, Suparmi. Determinant of Unintended Pregnancies in Indonesia [Secondary Data Analysis of Basic Health Reserach 2013]. Jurnal Kesehatan Reproduksi. 2016;7[1]:16-24.

[5] Exavery A, Kanté AM, Hingora A, Mbaruku G, Pemba S, Phillips JF. How Mistimed and Unwanted Pregnancies Affect Timing of Antenatal Care Initiation in Three Districts 
in Tanzania. BMC Pregnancy and Childbirth. 2013;13[35].

[6] WHO. Maternal mortality [Internet]. WHO. 2016 [cited 2019 Sep 21]. Available from: https://www.who.int/en/news-room/fact-sheets/detail/maternal-mortality

[7] Mohamed EA-EB, Hamed AF, Yousef FMA, Ahmed EA. Prevalence, Determinants, and Outcomes of Unintended Pregnancy in Sohag District, Egypt. Journal of the Egyptian Public Health Association. 2019;94[14].

[8] Sabahelzain MM, Abdalla SM, Meraj SA, Mohamed EY, Almansour MA, Medani KT, et al. Prevalence and Factors Associated with Unintended Pregnancy Among Married Women in An Urban and Rural Community, Khartoum State, Sudan. Global Journal of Medicine and Public Health. 2014;3[4]:1-8.

[9] Dott M, Rasmussen SA, Hogue CJ, Reefhuis J, National Birth Defects Prevention Study. Association Between Pregnancy Intention and Reproductive-health Related Behaviors Before and After Pregnancy Recognition, National Birth Defects Prevention Study, 1997-2002. Maternal and Child Health Journal. 2010;14[3]:373-81.

[10] Wado YD, Afework MF, Hindin MJ. Unintended Pregnancies and The Use of Maternal Health Services in Southwestern Ethiopia. BMC International Health and Human Rights. 2013;13[36].

[11] Khajehpour M, Simbar M, Jannesari S, Ramezani-Tehrani F, Maj HA. Health Status of Women with Intended and Unintended Pregnancies. Public Health. 2013;127[1]:58-64.

[12] Magadi MA, Madise NJ, Rodrigues RN. Frequency and Timing of Antenatal Care in Kenya: Explaining The Variations Between Women of Different Communities. Social Science \& Medicine. 2000;51[4]:551-61.

[13] Lau Y, Keung DWF. Correlates of Depressive Symptomatology During The Second Trimester of Pregnancy Among Hong Kong Chinese. Social Science \& Medicine. 2007;64[9]:1802-11.

[14] Lara MA, Navarro C, Navarrete L, Cabrera A, Almanza J, Morales F, et al. Depressive Symptoms in Pregnancy and Associated Factors in Patients of Three Health Institutions in Mexico City. Salud Mental. 2006;29[4]:55-62.

[15] Gipson JD, Koenig MA, Hindin MJ. The Effects of Unintended Pregnancy on Infant, Child, And Parental Health: A Review of The Literature. Studies in Family Planning. 2008;39[1]:18-38.

[16] Dibaba Y, Fantahun M, Hindin MJ. The Effects of Pregnancy Intention on The Use of 
Antenatal Care Services: Systematic Review and Meta-Analysis. Reproductive Health. $2013 ; 10[50]$.

[17] Parkhurst JO, Penn-Kekana L, Blaauw D, Balabanova D, Danishevski K, Rahman SA, et al. Health Systems Factors Influencing Maternal Health Services: A Four-Country Comparison. Health Policy. 2005;73[2]:127-38.

[18] Dini LI, Riono P, Sulistiyowati N. Pengaruh Status Kehamilan Tidak Diinginkan Terhadap Perilaku Ibu Selama Kehamilan dan Setelah Kelahiran Di Indonesia [Analisis Data SDKI 2012]. Jurnal Kesehatan Reproduksi. 2016;7[2]:119-33.

[19] Padila. Buku Ajar Keperawatan Maternitas. Yogyakarta: Nuha Medika; 2014.

[20] Sari KIP, Efendy HV. Analisis Faktor Yang Berpengaruh Terhadap Kunjungan Antenatal Care. Jurnal Keperawatan dan Kebidanan. 2017;9[1]:93-113.

[21] Awasthi MS, Awasthi KR, Thapa HS, Saud B, Pradhan S, Khatry RA. Utilization of Antenatal Care Services in Dalit Communities in Gorkha, Nepal: A Cross-Sectional Study. Journal of Pregnancy. 2018;2018.

[22] Mkandawire P, Atari O, Kangmennaang J, Arku G, Luginaah I, Etowa J. Pregnancy Intention and Gestational Age at First Antenatal Care [ANC] Visit in Rwanda. Midwifery. 2019;68:30-8.

[23] Dixit P, Ram F, Dwivedi LK. Determinants of Unwanted Pregnancies in India Using Matched Case-Control Designs. Pregnancy and Childbirth. 2012;12[84].

[24] Liu Y, Liu J, Ye R, Ren A, Li S, Li Z. Association of Education and Occurrence of Low Birthweight in Rural. American Journal of Public Health. 2008;98[4]:687-91.

[25] Habte D, Teklu S, Melese T, Magafu MGMD. Correlates of Unintended Pregnancy in Ethiopia: Results From a National Survey. PLoS ONE. 2013;8[12]:1-8. 